English, please). It would then be up to Professor Meyer and his fellow non-AngloSaxons to assert themselves and their respective languages in a new "melting pot." -I am, etc.,

Therwii, Switzerland

S. C. COOPER

\section{Overseas Doctors}

SIR,-I agree with Dr. R. J. Henderson 26 July, p. 229) when he says, "How could a three-month habilitation course, especially for someone whose English is weak, make up for the deficiencies of several years in an inferior medical school?" Better facilities should be provided in Britain for training overseas doctors. Indian doctors do come to Britain out of altruism because they have a great respect for things British. If they had money on their mind they would have gone to oil-rich countries and to America. They come to Britain for postgraduate training instead of going to America, in spite of the fact that many British graduates receive postgraduate training in America. The image of Britain as a centre for postgraduate studies in medicine has been eroded. As a result overseas doctors in this country are drifting fast to America for postgraduate training.

There is no denying the fact that a strong emotional reaction against immigrants, once confined to shop floors, is now affecting the medical profession. This trend has been perceptibly growing over the past decade and has now come to a head. Cheap labour was welcome in the factories only during the depression of the 1930s. So was cheap medical labour welcome when the N.H.S. badly needed overseas doctors. The General Medica! Council has shown a lack of sensitivity in dealing with the issue. The human element has been missing. The G.M.C. knows as well as anyone else that spoken English can be picked up only by being in this country. The English themselves have difficulty in learning the dialects of Scotland. Overseas doctors should be accepted for training on a basis of equality In America after passing the E.C.F.M.G. one is accepted for training on an equal footing with an American for internship and residency. But for training in Britain there are no assurances and no safeguards.

When an overseas doctor in this country does not come up to expectation it tends to hit the headlines and the response of the mass media verges on hysteria. The B.M.A should have intervened before as well as a the present juncture. It should have suggested that discussions on examinations for overseas doctors and their results should be held behind the scenes.-I am, etc.,

Maesteg. Mid-Glamorgan

NESAR AHMED

\section{Primary Care and the Elderly}

SIR,-The R.M.F. is to be congratulated on giving rcasonably good coverage of the recent Annual Representative Meeting at Leeds and also of the Annual Scientitic Meeting 26 July, p. 221).

I think, however, that it is regrettable that in the account of the symposium on Primary Care and the Elderly no comment was made on the important discussion following a question I myself put to the panel concerning hearing aids and the elderly. This was accepted by the expert panel as of extreme importance. In addition, questions about the precise role of calcium supplements in both the skeletal system and maybe in the C.N.S. were rather summarily dismissed. Also, because of lack of time, further question asking for the opinion of the panel on the acrimonious issue of euthanasia was conveniently dismissed, though at a time when there are so many experts clearly doing their utmost to further the care of the elderly there are yet other influential ones who support euthanasia. The B.M.A., quite rightly in my opinion has stated its view that euthanasia is to be condemned.'

The wider use of hearing aids would certainly help many of the elderly who find a progressive loss of hearing adding to a feeling of social isolation already present because of physical infirmities. Unfortunately attutudes to the physically disabled, aged or otherwisc infirm, are to say the least very laissez-faire. No wonder some imagine that some of their fellow human beings would be better out of this world! A little more thought and kindness might rectify this despicable attitude to the less privileged members of society.-I am, etc.,

Wetherby, Yorks

MaBEI, LOIS HaIGH

1 Britush. Medical fournai Supplement, 1969, 3, 66

\section{Control of Transient Cerebral Ischaemic} Altacks by Heparin

Sir,-We report the case of a patient with transient cerebral ischaemic attacks which did not respond to oral anticoagulants, but appeared to be effectively controlled by small doses of heparin given subcutaneously.

The patient, a previously healthy man aged 59, awoke in the night feeling unwell and unable to move his left arm. On arrival at hospital two hours later his disability had recovered completely. Next day, however, he began to have repeated attacks of a burning sensation around the nose and lips, slurred speech, and left-sided weakness. Subsequently the episodes of hemiparesis alternated between left and right. His blood pressure was $150 / 80 \mathrm{~mm} \mathrm{Hg}$ in both arms, all pulses were readily palpable, and no arterial bruits were heard. During attacks he exhibited dysarthria, nystagmus, and pyramidal signs in the limbs with sensory impairment, sometimes on the right and sometimes on the left. He remained conscious and lucid throughout though he was incontinent on occasions. Transient ischaemic attacks in vertebrobasilar territory were diagnosed. His blood count, blood urea ritrogen, blood sugar, cholesterol, lipid profile, and tests for syphilis were satisfactory, as were radiographs of chest and skull. An E.C.G. showed a partial bundle-branch block attributed to ischaemia. A continuous heparin infusion $(10000 \mathrm{U}$ in $6 \mathrm{~h}$ ) was given on the third day in hospital and the ischaemic attacks ceased within hours. At the same time warfarin by mouth was given. After $48 \mathrm{~h}$ the heparin infusion was discontinued, but two days later the ischaemic attacks began again despite more than adequate oral anticoagulation (British Ratio 5.2). Attacks recurred with increasing frequency over the next five days, when heparin was reintroduced by the subcutaneous route in a dosage of $5000 \mathrm{U}$ every $12 \mathrm{~h}$ using a solution containing $25000 \mathrm{U} / \mathrm{ml}$. There were two further slight ischaemic attacks $48 \mathrm{~h}$ later, which then ceased. The injections were continued after discharge from hospital. Warfarin was withdrawn after a month without ill effect and the patient continued the heparin regimen for 10 weeks without complications. Two weeks after heparin was withdrawn the patient had one further attack and is currently taking aspirin and dipyridamole.

Several studies point to the usefulness of small doses of heparin given subcutaneously in preventing venous thrombosis after surgery. The precise way in which the low circulating levels of heparin act is not yet clear, but recent experimental work suggests this may be through enhancing the natural inhibitory property of plasma against thrombin and activated factor X.12 Theoretically the formation of thrombi within the arterial system may be less susceptible to influence by heparin, which can enhance the adriesion of platelets to collagen and their aggregation one to another. On the other hand, inhibition of the platelet release reaction by heparin may be more important in preventing subsequent embolization, and it is in this context that our observations are of interest. If confirmed they could provide a method of management in a clinical situation unresponsive to conventional therapy and fraught with the risk of a major stroke.-We are, etc.,

Paul Millac KFITH WOOD

Departments of Neurology and Haematology, Roya: Infirmary,

1 Han, P., and Ardlie, N. G., British Fournal of Hacmatology, 1974, 27, 253.

Yin, E. T., Wessler, S., and Stoll, P., Fournal of
Bioligical Chemistry, 1971, 246, 3694, 3703 3712

Excessive Use of Psychiatric Services by Suicidal Patients

Sik,-I was somewhat surprised to find that in their paper (26 July, p. 216) Dr. D. J. Pallis and his co-workers quoted some figures I had reported at a conference in September 1974. In their introduction, when reviewing findings on the frequency of suicide attempts in psychiatric patients, they said: "A more recent survey in Oxford showed that one in every 11 inpatients or day-patients had attempted suicide over a six-month period -a rate of 8800 per 100000 patient population." I would like to comment on this statement partly for the sake of clarification. My study was a one-year prospective survey of persons carrying out deliberate acts of self-poisoning or self-injury while psychiatric inpatients or day-patients. In the context in which it occurred in Dr. Pallis and his colleagues' paper the statement could have been interpreted as referring to the number of patients found to have a previous history of such behaviour. I would in any case be loath to use the term "attempted suicide" to describe the majority of these acts since many involved, for example, minimal cutting of the skin.

Since the figures quoted referred to the first six months of the study and were provisional I feel I should give the final findings. The overall rate for this behaviour was 3330 per 100000 patients at risk (or one in every 30 ), which is considerably less than the figure that was quoted. Of more relevance to Dr. Pallis and his colleagues' study are my findings on scrutinizing the case notes of a consecutive series of 300 psychiatric hospital patients, when I found that at least 
$34 \%$ had a previous history of self-poisoning or self-injury.-I am, etc.,

Warneford Hospital,

KEITH HAWTON

\section{Emigration of Doctors}

SIR,-One aspect of the continuing debate engendered by the two articles by Dr. B. Senewiratne (15 March, p. 618, and 22 March, p. 669), and amplified in a "brief and dogmatic" manner by Dr. M. P. White (7 June, p. 561), deserves further comment. I refer to the paramedical worker who is "only too delighted" to go to rural areas and to Dr. White's unfortunate experiences that lead him to assert (a) that such workers do not exist; $(b)$ that if they do their isolation necessarily induces substandard work; and (c) that the deployment of such workers lowers the standard of medical care. Far from ignoring unacceptable and unassimilable facts, I submit that the great bulk of evidence from many developing countries contradicts these three assertions, and I welcome the growing interest in the whole subject of the role of auxiliary medical workers in health care.

Having been principal for 23 years of school in a developing country for training such auxiliaries and having seen the trained product at work-adequately supervised and adequately supplied with drugs and equipment-I may confidently assert that such health workers do exist. In the past few years I have seen them in many countries, in all continents. Their work is being documented in professional journals. Admittedly, if left unsupervised in an isolated setting, an inadequately motivated medical auxiliary may not maintain the standards he has reached in his training school. But if the medical officer in charge can, with infectious enthusiasm and competence, periodically visit the medical auxiliaries for whose work he is responsible and develop a comprehensive health programme for the district, then isolation and falling standards are not the inevitable hallmarks of a disillusioned service.

The World Health Organization and other interested bodies are now convinced that the only way to ensure that health facilities become more widely and equitably distributed in the world is by the deployment of appropriately trained and adequately supervised medical auxiliaries. The stark choice in many developing countries is now seen to be between an expensive Western-orientated curative service for the privileged few and a system of "medical care" (in the larger sense) mediated by medical auxiliaries. The training and motivation of the new generation of doctors who will implement and develop these concepts are matters of increasing importance to governments and medical schools at home and abroad.-I am, etc.,

Leprosy Study Centre

S. G. BRownE

London $W .1$

\section{Private Practice and the N.H.S.}

SIR,-Tc those familiar with the methods of the present Government and of the bureaucracy that feeds upon medicine it will come as no surprise that the grotesquely misnamed "consultative document" was issued by the Department of Health and
Social Security on 11 August after Parliament had risen, requesting comments before the end of September. The profession is indebted to you for publishing the document in full (23 August, p. 497), but it is a pity that your sound comment should appear as the last leading article (p. 452) under the rather inconspicuous title "No Case for Change."

There is indeed a case for change, but it is precisely in the opposite direction to that advocated by the Government. Experience of the use of pay-beds in regional and district hospitals has convinced me that the mixed medical economy is of benefit to all patients. Moreover, if the hospital management committees in the past (now replaced by a more remote and impersonal administration) had retained the pay-bed charges instead of returning them to the Treasury there would have developed a wholly healthy local vested interest in the proper management of private accommodation. Hospitals would have come tc regard such facilities as a small but integral part of an all-round service to the public.

The abolition of private facilities in our hospitals is but one step on the road to totalitarian control of medicine and ultimately of the whole economy. General practitioners should not be deceived into thinking that they are immune. It will not be long before they too are informed that private patients may not be dealt with in the same premises as N.H.S. patients. And if they comfort themselves with the thought that many of them own their premises the Government would soon find an excuse for takeover of accommodation or for limitation of ancillary help to those who pledge themselves to the pristine purity of state medicine.

In view of the proposed system of control and inspection of independent hospitals and control over advertising of private medical facilities (paras. 6-8) it is astonishing to read the initial comment attributed to the British United Provident Association that there was "no real threat" in Mrs. Castle's proposals; I pray that someone in that organization has now taken the trouble to study the document properly.

The suggestion in the document (para. 9) that the aim of licensing is to ensure that the private sector complies with minimum criteria could surely be applied to the N.H.S. too with considerable benefit. A truly independent inspectorate to ensure maintenance of standards in all hospitals might commend itself to the public, but I am not in favour of providing a state department and its agencies with powers to snoop upon and control the activities of the private sector alone.

The document goes on (para. 10) to explain that a second objective of licensing is to ensure that "scarce skills achieved by training at public expense" are not hived off from the N.H.S. The Government should be reminded that scarce skills, though of ten partly supported at public expense, are mainly achieved by the industry, application, and sacrifice of dedicated and determined individuals who sometimes earn less than many of the unskilled workers and others who so often disrupt society today.

Let no doctor be under any illusion about the Draconian implications of the proposals made in this monstrous document. The public too must recognize that its own freedom is at stake. The only sound reaction is that of implacable opposition to the intentions of the Government. In these circumstances the whole profession should follow the lead given by the Joint Consultants Committee (representing the royal colleges and faculties, the B.M.A., and the British Dental Association) when, on 15 October 1974, it pledged its "full support to the preservation of private practice both within and outside the N.H.S., including the retention of private beds in the public sector" (26 October, p. 241). That pledge was fully supported by the Hospital Staffs Conference and the Annual Representative Meeting of the B.M.A. in 1975.-I am, etc.,

Radlett. Herts

Reginald S. MURLey

SIR,-Mrs. Castle's Consultative Document on the abolition of private practice in N.H.S hospitals has been published (23 August, p 497) and is of such importance that any doctor, N.H.S. or otherwise, concerned with private practice or not, should study it. They will thereby learn that it is about power and politics and not about the health of the nation.

For instance: (a) Mrs. Castle proposes abolition of private practice in N.H.S. hospitals for tax-paying citizens but not for foreigners; $(b)$ she accepts that rationing of medical facilities will be necessary (? by whom) and yet insists that the private sector, which could prevent the need for rationing, shall not expand; $(c)$ where she allows an application for a private institution to proceed this will have to be advertised in newspapers circulating in a diameter of 100 miles, and this can be only to attract widespread left-wing objections at the automatic public inquiry which follows; (d) medical confidentiality, already largely lost in N.H.S hospitals, is to be threatened in private hospitals, which will have, as a condition of licensing, to make returns on work carried out; (e) quality of premises and staff in private institutions will be a condition of licensing, while the same criteria do not apply to N.H.S. institutions; $(f)$ where N.H.S. facilities and staffing are inadequate private facilities shall not be permitted, though they would result in overall improvement in services to the area.

Combine all this with the recently promulgated requirement that certain future consultant appointments will be conditional upon willingness to be involved with carrying out terminations of pregnancy and one can see a systematic attack on the independence of medical practice. May I call on all medical colleagues of all interests, N.H.S., private, or both, general practitioner or specialist, junior or senior, to close ranks now and to resist this and all other incursions on the integrity and independence of the profession by bureaucrats and politicians? $-\mathrm{I}$ am, etc.,

\section{G. MITFORD-BARBERTON}

Irthlingborough, Northants

SIR,-In the consultative document on pristates: "Legislation will also provide for outpatient facilities in N.H.S. hospitals to be withdrawn." This needs clarification from the Department of Health and Social 